Case Report

\title{
Aesthetic Depigmentation of Gingival Smoker's Melanosis Using Carbon Dioxide Lasers
}

\author{
Luis Silva Monteiro, ${ }^{1,2}$ José Adriano Costa, ${ }^{1}$ Marco Infante da Câmara, ${ }^{1}$ Rui Albuquerque, ${ }^{3}$ \\ Marco Martins, ${ }^{2}$ José Júlio Pacheco, ${ }^{1}$ Filomena Salazar, ${ }^{1}$ and Fernando Figueira ${ }^{1,2}$ \\ ${ }^{1}$ Medicine and Oral Surgery Department and Institute of Research and Advanced Training in Health Sciences and \\ Technologies (IINFACTS), Higher Institute of Health Sciences (ISCS-N), CESPU, 4585-116 Paredes, Portugal \\ ${ }^{2}$ Stomatology and Dental Medicine Department (CESPU), Centro Hospitalar de São João, Polo de Valongo, 4440-563 Valongo, Portugal \\ ${ }^{3}$ Oral Medicine Department, Birmingham Dental Hospital, School of Dentistry, University of Birmingham, Birmingham B4 6NN, UK
}

Correspondence should be addressed to Luis Silva Monteiro; lmonteiro.md@gmail.com

Received 11 January 2015; Revised 20 March 2015; Accepted 24 March 2015

Academic Editor: Maddalena Manfredi

Copyright $\odot 2015$ Luis Silva Monteiro et al. This is an open access article distributed under the Creative Commons Attribution License, which permits unrestricted use, distribution, and reproduction in any medium, provided the original work is properly cited.

Melanic pigmentation results from melanin produced by the melanocytes present in the basal layer of the oral epithelium. One of the most common causes of oral pigmentation is smoker melanosis, a condition associated with the melanocyte stimulation caused by cigarette smoke. This paper aims to illustrate the use of a carbon dioxide laser in the removal of the gingival melanic pigmentation for aesthetic reasons in a 27-year-old female patient with history of a smoking habit. The carbon dioxide laser vaporisation was performed on the gingival mucosa with effective and quick results and without any complications or significant symptoms after the treatment. We conclude that a carbon dioxide laser could be a useful, effective, and safe instrument to treat the aesthetic complications caused by oral smoker melanosis.

\section{Introduction}

Gingivae are an important component of masticatory mucosa, contributing not only to the mastication process but also to anatomic and aesthetic characteristics of the individuals. The colour of the gums is determined by the thickness of epithelium, keratinisation degree, the presence and degree of melanin deposition, and the underlying connective tissue, including blood irrigation with presence of other pigments such as haemoglobin or oxyhemoglobin $[1,2]$. The melanocytes are seen in the basal layer of the epithelium. They release melanin granules through the dendrite projections to the interior of the adjacent keratinocytes [3]. Melanin is a granular endogenous nonhaemoglobinic pigment that gives a brown or black colour (eumelanin) to the skin, mucosa, hair, and eye or sometimes a reddish colour (pheomelanin) [2]. Besides the colouration of the tissues the main function of this pigment is photoprotection, protecting the DNA from the UV rays [4].
The accumulation or increased deposition of melanin on oral mucosa can be physiological and called "racial pigmentation" or caused by several stimulants including trauma, infection, inflammation (recalcitrant lichen planus, lichenoid lesions, pemphigus, or pemphigoid), systemic disorders (Addison disease, Peutz-Jeghers disease, LaugierHunziker syndrome, or Albright disease), or drugs (clotrimazole, tetracycline, colchicine, and ketoconazole) [2, 57]. Smoking can also cause an excessive deposition of melanin in the oral epithelial layer of oral mucosa. Polycyclic amines such as nicotine and benzopyrenes, present in tobacco, can activate the melanocytes to produce melanin, perhaps as a protective adaptation of oral mucosa against tobacco agents [8]. Tobacco-associated melanin pigmentation (smoker melanosis) has been reported in $22 \%$ of smokers and is dose-dependent [9]. Women are more affected and the characteristic presentation is a diffuse black-brown macule that can involve mainly the gingiva, followed by buccal mucosa, lips, and hard palate [9]. Diagnosis is based on 
clinical characteristics and on smoking history in addition to the exclusion of physiological pigmentation, systemic causes such as Addison disease, hemochromatosis, and drug induced pigmentations [5]. Use of biopsy is an important method when malignancy is suspected or even to confirm clinical diagnosis [10]. Several techniques that have been developed aimed at the removal of the gingival melanic pigmentation for aesthetic reasons such as gingival surgical abrasions, scalpel gingivectomy, laser vaporization, cryosurgery, electrosurgery, chemical methods, and gingival grafts [11-18]. Lasers have been proposed as a useful method for the removal of the gingival melanic pigmentations. The advantages of lasers include haemostatic capacity, no need for sutures, and fewer postoperative complications such as pain, oedema, or infections [19-21]. The most used lasers are the carbon dioxide $\left(\mathrm{CO}_{2}\right)$ laser $(10,6 \mu \mathrm{m})[15,22,23]$, Nd:YAG $(1,064 \mu \mathrm{m})$ [24], Er:YAG $(2,94 \mu \mathrm{m})$ [23, 25, 26], Argon (448 nm and $514 \mathrm{~nm})$ [27], and high power diodes $(808 \mathrm{~nm}, 810 \mathrm{~nm}$, and $830 \mathrm{~nm})[25,28]$. The aim of this paper is to:

(i) explain a case report, about a Portuguese female, who had $\mathrm{CO}_{2}$ laser treatment for the removal of gingival melanic pigmentation,

(ii) carry out a literature review.

\section{Clinical Case}

A 27-year-old Caucasian female was referred to the Stomatology and Dental Medicine Department (CESPU) of the Centro Hospitalar de São João, Pólo de Valongo, Oporto, Portugal. Her chief complaint was of a "dark-colour lower gum" and she made the request for rapid cosmetic therapy. She reported noticing darkening of the teeth and gums for over two years, mainly in the mandible. No symptoms and no significant personal or family history were present. The patient denied taking any medication or any other dark pigmentation in other locations. Her blood pressure was within the normal range of values. She had stopped smoking a year before the consultation, although she had smoked 30 cigarettes per day for more than 10 years. On oral examination two blackbrown macules measuring $1 \times 1 \mathrm{~cm}$ were detected in the vestibular attached lower gingiva (Figure 1). There was no lymphadenopathy or salivary gland abnormalities detected. Previous incisional biopsy to rule out any malignancy and blood investigations (complete full blood count and general biochemistry, including cortisol and ACTH serum levels) showed no abnormalities or potential causes. A diagnosis of smoker's melanosis was given based on the smoking history and the absence of any abnormalities seen in previous investigations. After explaining the benign character of the pigmentation, the patient requested the elimination of the pigmentation by aesthetic reasons due to professional work issues. $\mathrm{A} \mathrm{CO}_{2}$ laser vaporization for gingival depigmentation was proposed. The vaporization of the pigmentation was performed under local anaesthesia (2\% lidocaine with $1: 100,000$ epinephrine) with $\mathrm{CO}_{2}$ laser $(10600 \mathrm{~nm})$ (DEKA Smart US20D, Florence, Italy), with angulated mirror, focus spot of $1 \mathrm{~mm}$, pulsed mode $(50 \mathrm{~Hz}), 4.5 \mathrm{~W}$ of output power, power density of $573.25 \mathrm{~W} / \mathrm{cm}^{2}$, and fluence of $11.46 \mathrm{~J} / \mathrm{cm}^{2}$

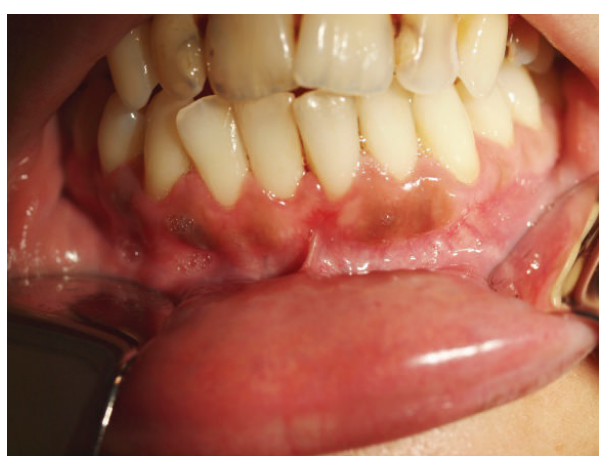

FIGURE 1: Initial clinical appearance with melanotic macules located on lower buccal gingiva.

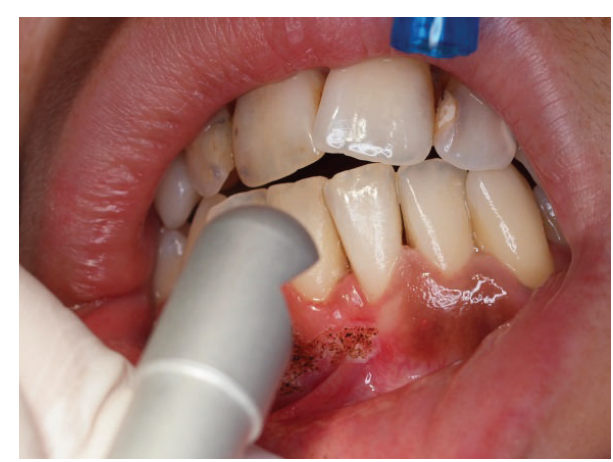

FIGURE 2: Vaporisation with $\mathrm{CO}_{2}$ laser of gingival macules.

(Figure 2). During this procedure, safety precautions were in place to protect the operator, assistant, and patient. With this laser procedure, the secondary-intention healing of the surgical wound was reached without any dressing (Figure 3). Paracetamol (1 g every 12 hours) was prescribed for two days to be taken only if she developed painful symptoms. After 3 weeks, wound healing was completed uneventfully without any melanin pigmentation (Figure 4 ). She did not report any postoperative pain, swelling, or other complications. After two years of follow-up, the patient had no symptoms or signs of gingival melanin pigmentation.

\section{Discussion}

The term "smoker's melanosis" was described by Hedin et al. in 1977 to characterise a benign limited melanin pigmentation occurring in the attached gingiva of tobacco smokers [29]. Through the stimulation, by polycyclic amines, smoking causes the activation of melanocytes to produce melanin [8]. These manifestations of pigmentation are considered normal and generally no treatment is recommended except for aesthetic purposes [2, 30]. Tobacco cessation has been reported to be sufficient in eliminating pigmentation [8]. However, in the present case, the patient claimed that she had stopped smoking one year previously and yet the gingival pigmentation had not disappeared. She asked us for a rapid way to eliminate this pigmentation. 


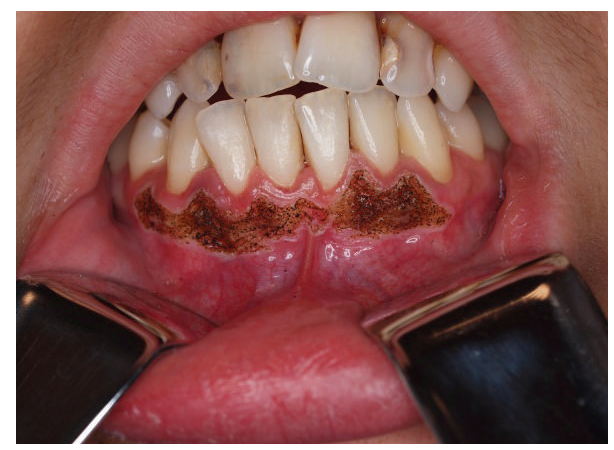

FIgURE 3: Clinical appearance after $\mathrm{CO}_{2}$ vaporisation procedure.

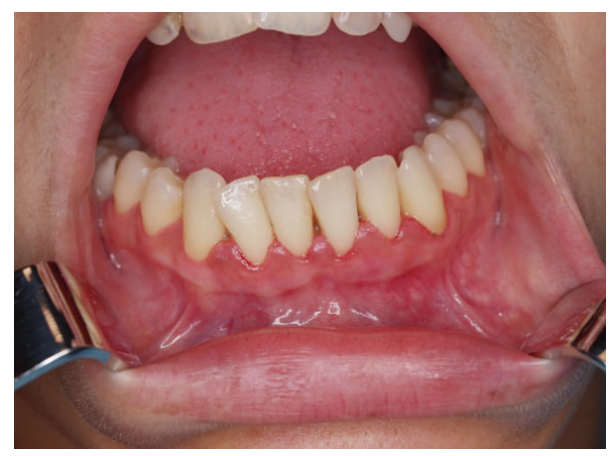

FIGURE 4: Clinical image of the lower anterior gingiva 3 weeks after $\mathrm{CO}_{2}$ vaporisation procedure without recurrence.

The first procedure for the removal of gingival pigments, for aesthetical reasons, dates back to 1946, where an exfoliative method was used which was $90 \%$ phenol-based. The method presented limitations due to the quick draining and penetration in the gingival mucosa [16]. Since then several techniques have been developed including gingival abrasions (which involves the removal of the epithelium of pigmented areas using a high speed hand piece and diamond bur) $[14,26]$, gingivectomy (using a scalpel in which the gingival epithelium is removed as well as a layer of connective tissue, allowing secondary intention healing) [14, 17], cryosurgery (resorting to local necrosis through fast freezing), and gingival grafts [11, 13]. These techniques have been associated with some limitations such as lack of precision during surgery, lack of visibility of the tissue elimination especially for chemical and cryosurgery, hemorrhaging, and the need for dressings in gingivectomy techniques [11, 13, 17]. Lasers present several advantages in the treatment of oral tissues including precision cutting with possibility of histological analysis and a good visualisation of the surgical field in which there is coagulation during tissue elimination and therefore there is no necessity for any sutures [19-21]. When compared with conventional surgery, there are fewer risks of other complications commonly seen, such as pain, edema, and infection $[19,20,31]$. We could confirm these advantages in our case, as the patient did not report any pain, swelling, or other complications.
Several lasers have been used in depigmentation of oral melanotic macules $[15,24,25,28]$. When looking at the different types of laser, it is possible to establish a relation between the type of biological effects and the wavelength used. The depth of penetration of each type of laser in the biological tissues varies according to the absorption of this energy $[15,24,25,28,32]$. Considering the localisation of the melanocytes in the epithelium, lasers with a superficial effect could be indicated, such as a $\mathrm{CO}_{2}$ laser. $\mathrm{CO}_{2}$ lasers are reported to cause minimal damage to the periosteum and bone beneath the gingiva but have a sufficient deep penetration $(0.1 \mathrm{~mm})$ to reach the melanocytes present pigmented areas $[15,33,34]$. Successful application of other lasers has been reported such as Nd:YAG or diode laser using melanin as chromophore $[24,25,28]$. However, the deep penetration of these wavelengths ( 4 to $6 \mathrm{~mm}$ ) in the tissue could lead to several complications including bone necrosis or gingival fenestration as observed by Atsawasuwan et al. [24] when using Nd:YAG laser.

The final result we present in this case was achieved with one session. However, Nakamura et al. [22] reported the need for repeated sessions using a $\mathrm{CO}_{2}$ laser, in a continuous mode. The use of the pulsed mode as performed in the present case may avoid the carbonisation of tissues which allows a good visualisation of the surgical field. This could allow the elimination of the entire pigment present in the gingiva [33]. The number of cohort studies showing recurrence after laser appliance is limited. Ozbayrak et al. [15] observed no recurrence of gingival melanotic pigmentations in the 18 months after $\mathrm{CO}_{2}$ laser ablation. Kaya et al. [25] did not find any recurrence using Er:YAG and diode lasers in 20 patients with gingival melanotic pigmentations. However, repigmentation has been reported by others [17, 22]. Smoking may influence the success of the treatment. Esen et al. [33] performed depigmentation of gingival melanin pigmentation in 10 patients and observed a recurrence in 2 patients which were both smokers. Tobacco cessation may be mandatory to avoid repigmentation.

In conclusion, this case illustrates that $\mathrm{CO}_{2}$ lasers are a useful, effective, and safe application method in the removal of the gingival melanin pigmentation when tobacco cessation has not improved the appearance. However, longer cohort studies are needed for a better understanding of the potential benefits of this method.

\section{Conflict of Interests}

The authors declare that there is no conflict of interests.

\section{References}

[1] D. Eisen, "Disorders of pigmentation in the oral cavity," Clinics in Dermatology, vol. 18, no. 5, pp. 579-587, 2000.

[2] M. Meleti, P. Vescovi, W. J. Mooi, and I. van der Waal, "Pigmented lesions of the oral mucosa and perioral tissues: a flow-chart for the diagnosis and some recommendations for the management," Oral Surgery, Oral Medicine, Oral Pathology, Oral Radiology and Endodontology, vol. 105, no. 5, pp. 606-616, 2008. 
[3] A. W. Barrett and C. Scully, "Human oral mucosal melanocytes: a review," Journal of Oral Pathology and Medicine, vol. 23, no. 3, pp. 97-103, 1994.

[4] M. J. Hicks and C. M. Flaitz, "Oral mucosal melanoma: epidemiology and pathobiology," Oral Oncology, vol. 36, no. 2, pp. 152-169, 2000.

[5] S. Müller, "Melanin-associated pigmented lesions of the oral mucosa: presentation, differential diagnosis, and treatment," Dermatologic Therapy, vol. 23, no. 3, pp. 220-229, 2010.

[6] A. Kauzman, M. Pavone, N. Blanas, and G. Bradley, "Pigmented lesions of the oral cavity: review, differential diagnosis, and case presentations," Journal of the Canadian Dental Association, vol. 70, no. 10, pp. 682-683, 2004.

[7] G. Mergoni, S. Ergun, P. Vescovi, Ö. Mete, H. Tanyeri, and M. Meleti, "Oral postinflammatory pigmentation: an analysis of 7 cases," Medicina Oral, Patologia Oral y Cirugia Bucal, vol. 16, no. 1, Article ID 16953, pp. el1-e14, 2011.

[8] C. A. Hedin, J. J. Pindborg, and T. Axell, "Disappearance of smoker's melanosis after reducing smoking," Journal of Oral Pathology \& Medicine, vol. 22, no. 5, pp. 228-230, 1993.

[9] T. Axell and C. A. Hedin, "Epidemiologic study of excessive oral melanin pigmentation with special reference to the influence of tobacco habits," Scandinavian Journal of Dental Research, vol. 90, no. 6, pp. 434-442, 1982.

[10] N. Matsumoto, T. Kitano, H. Oki et al., "Pigmented oral carcinoma in situ: a case report and literature review," Oral Surgery, Oral Medicine, Oral Pathology and Oral Radiology, vol. 118, no. 3, pp. e79-e83, 2014.

[11] C.-J. Yeh, "Cryosurgical treatment of melanin-pigmented gingiva," Oral Surgery, Oral Medicine, Oral Pathology, Oral Radiology, and Endodontics, vol. 86, no. 6, pp. 660-663, 1998.

[12] M. Tamizi and M. Taheri, "Treatment of severe physiologic gingival pigmentation with free gingival autograft," Quintessence International, vol. 27, no. 8, pp. 555-558, 1996.

[13] M. Talebi, N. Farmanbar, S. Abolfazli, and A. Sarraf Shirazi, "Management of physiological hyperpigmentation of oral mucosa by cryosurgical treatment: a case report," Journal of Dental Research, Dental Clinics, Dental Prospects, vol. 6, no. 4, pp. 148-151, 2012.

[14] S. Parwani and R. Parwani, "Achieving better esthetics by gingival de-pigmentation: report of three cases with a review of the literature," The Journal of the Michigan Dental Association, vol. 95, no. 2, pp. 52-78, 2013.

[15] S. Ozbayrak, A. Dumlu, and S. Ercalik-Yalcinkaya, "Treatment of melanin-pigmented gingiva and oral mucosa by $\mathrm{CO}_{2}$ laser," Oral Surgery, Oral Medicine, Oral Pathology, Oral Radiology, and Endodontics, vol. 90, no. 1, pp. 14-15, 2000.

[16] A. Hasegawa and H. Okagi, "Removing melagenous pigmentation using 90 percent phenol with 95 percent alcohol," Dental Outlook, vol. 42, pp. 673-676, 1973.

[17] O. Bergamaschi, S. Kon, A. I. Doine, and M. P. Ruben, "Melanin repigmentation after gingivectomy: a 5-year clinical and transmission electron microscopic study in humans," International Journal of Periodontics \& Restorative Dentistry, vol. 13, no. 1, pp. 85-92, 1993.

[18] Y. H. Lin, Y. K. Tu, C. T. Lu et al., "Systematic review of treatment modalities for gingival depigmentation: a randomeffects poisson regression analysis," Journal of Esthetic and Restorative Dentistry, vol. 26, no. 3, pp. 162-178, 2014.

[19] L. S. Monteiro, J. Mouzinho, A. Azevedo, M. I. da Câmara, M. A. Martins, and J. M. la Fuente, "Treatment of Epulis Fissuratum with carbon dioxide laser in a patient with antithrombotic medication," Brazilian Dental Journal, vol. 23, no. 1, pp. 77-81, 2012.

[20] U. Romeo, C. Russo, G. Palaia et al., "Biopsy of different oral soft tissues lesions by KTP and diode laser: histological evaluation," The Scientific World Journal, vol. 2014, Article ID 761704, 6 pages, 2014.

[21] E. Merigo, F. Clini, C. Fornaini et al., "Laser-assisted surgery with different wavelengths: a preliminary ex vivo study on thermal increase and histological evaluation," Lasers in Medical Science, vol. 28, no. 2, pp. 497-504, 2013.

[22] Y. Nakamura, M. Hossain, K. Hirayama, and K. Matsumoto, "A clinical study on the removal of gingival melanin pigmentation with the $\mathrm{CO}_{2}$ laser," Lasers in Surgery and Medicine, vol. 25, no. 2, pp. 140-147, 1999.

[23] R. Hegde, A. Padhye, S. Sumanth, A. S. Jain, and N. Thukral, "Comparison of surgical stripping; Erbium-doped:yttrium, aluminum, and garnet laser; and carbon dioxide laser techniques for gingival depigmentation: a clinical and histologic study," Journal of Periodontology, vol. 84, no. 6, pp. 738-748, 2013.

[24] P. Atsawasuwan, K. Greethong, and V. Nimmanon, "Treatment of gingival hyperpigmentation for esthetic purposes by Nd:YAG laser: report of 4 cases," Journal of Periodontology, vol. 71, no. 2, pp. 315-321, 2000.

[25] G. Ş. Kaya, G. Y. Yavuz, M. A. Sümbüllü, and E. Day, "A comparison of diode laser and Er:YAG lasers in the treatment of gingival melanin pigmentation," Oral Surgery, Oral Medicine, Oral Pathology and Oral Radiology, vol. 113, no. 3, pp. 293-299, 2012.

[26] K. M. Lee, D. Y. Lee, S. I. Shin, Y. H. Kwon, J. H. Chung, and Y. Herr, "A comparison of different gingival depigmentation techniques: ablation by erbium:yttrium-aluminum-garnet laser and abrasion by rotary instruments," Journal of Periodontal and Implant Science, vol. 41, no. 4, pp. 201-207, 2011.

[27] M. A. Trelles, W. Verkruysse, J. M. Segui, and A. Udaeta, "Treatment of melanotic spots in the gingiva by argon laser," Journal of Oral and Maxillofacial Surgery, vol. 51, no. 7, pp. 759761, 1993.

[28] A. Yousuf, M. Hossain, Y. Nakamura, Y. Yamada, J. Kinoshita, and K. Matsumoto, "Removal of gingival melanin pigmentation with the semiconductor diode laser: a case report," Journal of Clinical Laser Medicine and Surgery, vol. 18, no. 5, pp. 263-266, 2000.

[29] C. A. Hedin, "Smokers' melanosis. Occurrence and localization in the attached gingiva," Archives of Dermatology, vol. 113, no. 11, pp. 1533-1538, 1977.

[30] H. Dadlani, A. Bhardwaj, H. Grover, A. Yadav, and S. Lal, "Evaluation of patient response and recurrence of pigmentation following gingival depigmentation using laser and scalpel technique: a clinical study," Journal of Indian Society of Periodontology, vol. 18, no. 5, pp. 586-592, 2014.

[31] M. M. Soliman, Y. Al Thomali, A. Al Shammrani, and H. El Gazaerly, "The use of soft tissue diode laser in the treatment of oral hyper pigmentation," International Journal of Health Sciences, vol. 8, no. 2, pp. 133-140, 2014.

[32] P. Vescovi, L. Corcione, M. Meleti et al., "Nd:YAG laser versus traditional scalpel. A preliminary histological analysis of specimens from the human oral mucosa," Lasers in Medical Science, vol. 25, no. 5, pp. 685-691, 2010.

[33] E. Esen, M. C. Haytac, I. A. Öz, Ö. Erdoğan, and E. D. Karsli, "Gingival melanin pigmentation and its treatment with the 
$\mathrm{CO}_{2}$ laser," Oral Surgery, Oral Medicine, Oral Pathology, Oral Radiology and Endodontology, vol. 98, no. 5, pp. 522-527, 2004.

[34] R. A. Convissar, "Laser biopsy artifact," Oral Surgery, Oral Medicine, Oral Pathology, Oral Radiology, and Endodontics, vol. 84, no. 5, article 458, 1997. 


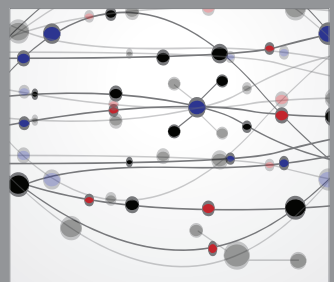

The Scientific World Journal
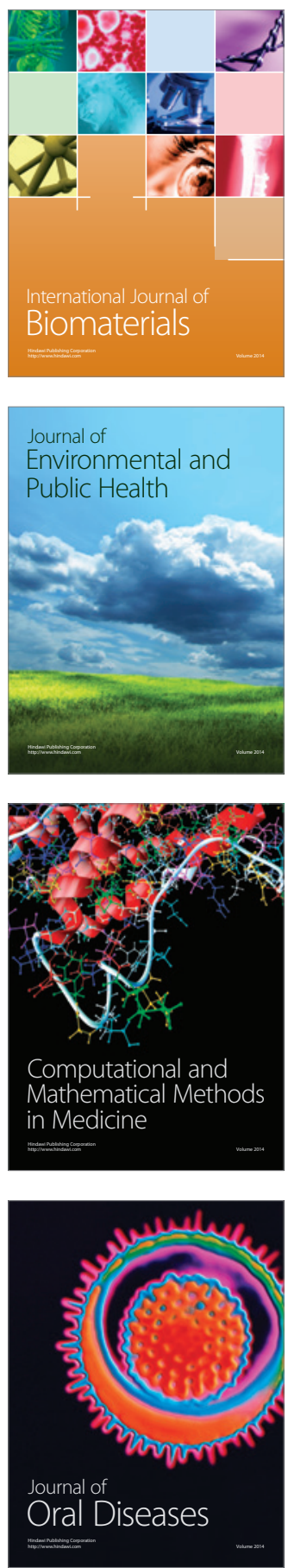
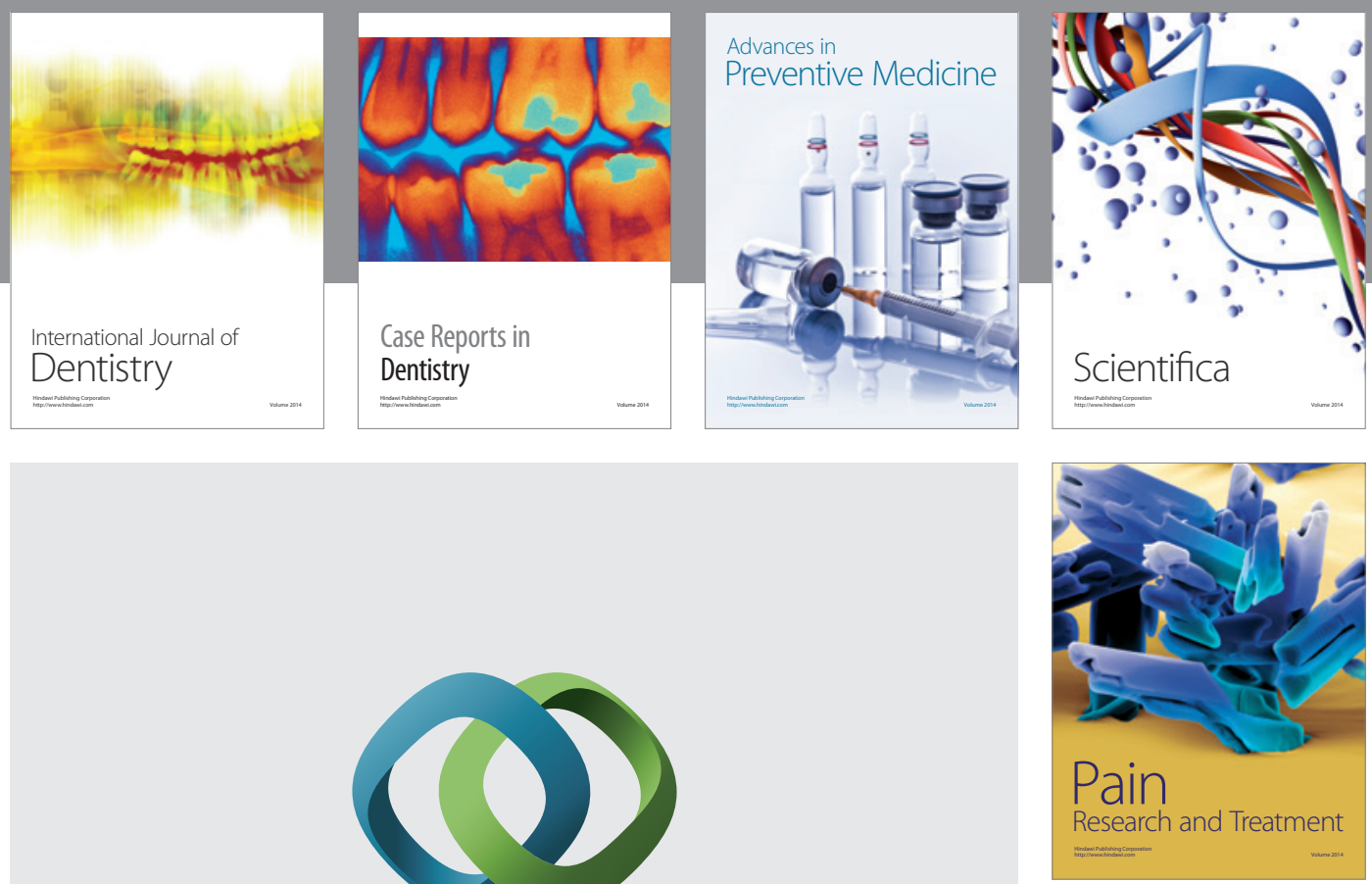

\section{Hindawi}

Submit your manuscripts at

http://www.hindawi.com
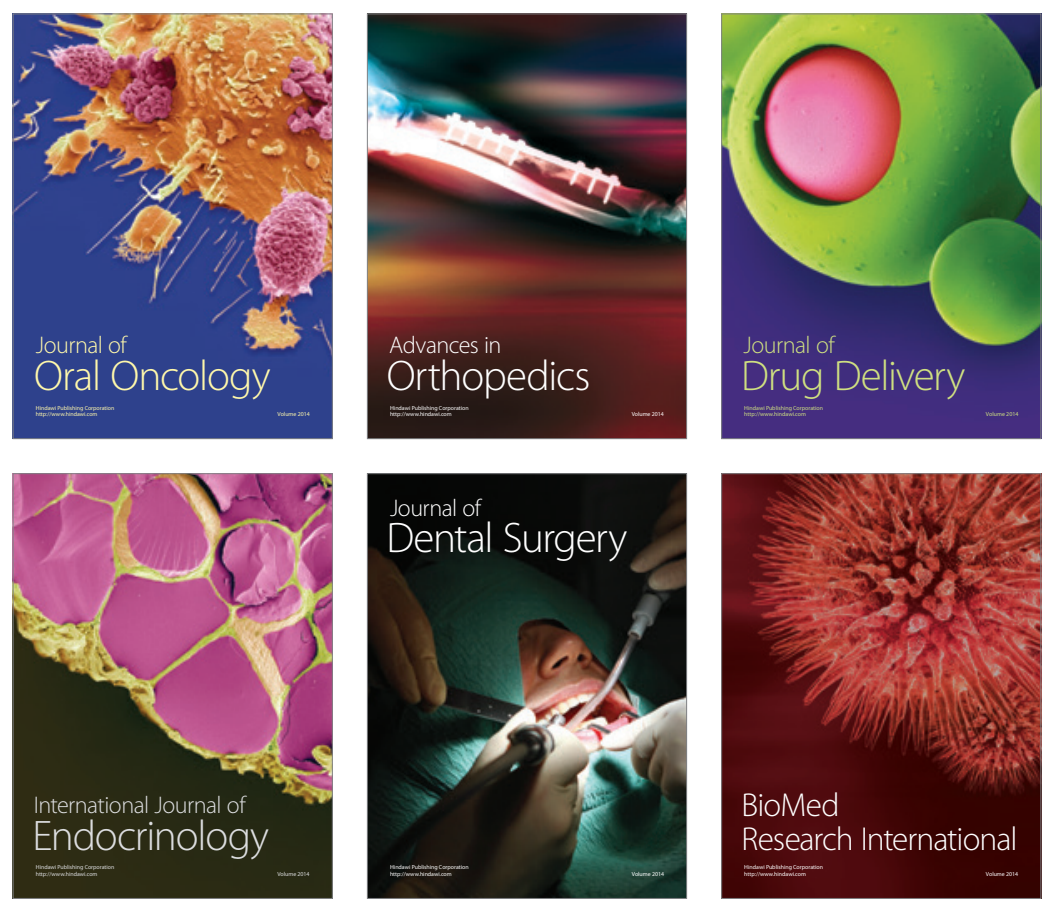

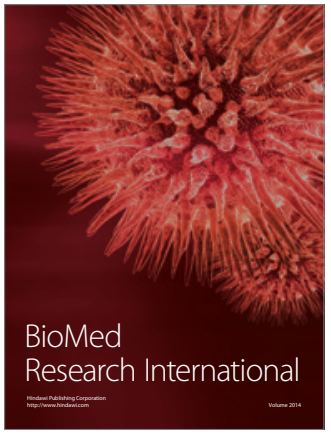

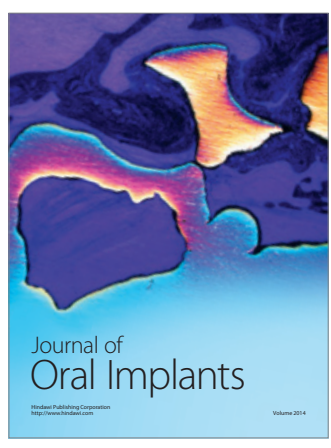
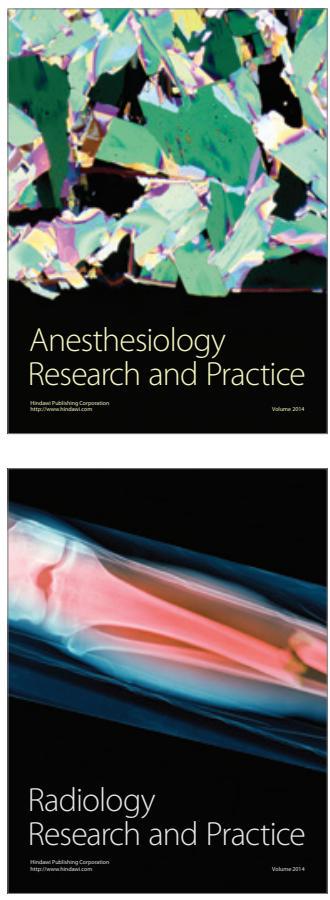